\title{
Conventional dual-cure versus self-adhesive resin cements in dentin bond integrity
}

\author{
Renata Andreza Talaveira da SILVA', Margareth COUTINHO², Pedro Igor CARDOZO', Larissa Alves da SILVA', \\ José Roberto ZORZATTO 3
}

\author{
1- Undergraduate student, School of Dentistry, Federal University of Mato Grosso do Sul, Campo Grande, MS, Brazil. \\ 2- PhD, Associate Professor, Department of Restorative and Prosthetic Dentistry, Faculty of Dentistry, Federal University of Mato Grosso do Sul, Campo \\ Grande, MS, Brazil. \\ 3- PhD, Associate Professor, Department of Statistics and Computing, Faculty of Computer Science, Federal University of Mato Grosso do Sul, Campo \\ Grande, MS, Brazil.
}

Corresponding address: Margareth Coutinho - Universidade Federal de Mato Grosso do Sul - Faculdade de Odontologia - Cidade Universitária - PO Box: 549 79070-900 - Campo Grande - MS - Brasil - Phone: +55-67-3345-7681 - +55-67-3345-7380 - e-mail: margarethcoutinho@uol.com.br

Received: May 24, 2009 - Modification: June 11, 2010 - Accepted: October 26, 2010

\section{ABSTRACT}

\begin{abstract}
$\mathrm{D}$ uring post preparation, the root canal is exposed to the oral cavity, and endodontic treatment may fail because of coronal leakage, bacterial infection and sealing inability of the luting cement. Objective: this study quantified the interfacial continuity produced with conventional dual-cure and self-adhesive resin cements in the cervical (C), medium (M) and apical (A) thirds of the root. Material and methods: Forty single-rooted human teeth were restored using Reforpost \# 01 conical glass-fiber posts and different materials ( $\mathrm{N}=10$ per group): group $\mathrm{AC}=$ Adper $^{\mathrm{TM}}$ ScotchBond ${ }^{\mathrm{TM}}$ Multi-purpose Plus + AllCem; group $A R C=$ Adper $^{T M}$ ScotchBond ${ }^{T M}$ Multi-purpose Plus + RelyX ARC; group U100=RelyX U100; and group MXC $=$ Maxcem Elite. After being kept in $100 \%$ humidity at $37^{\circ} \mathrm{C}$ for 72 hours, the samples were sectioned parallel to their longitudinal axis and positive epoxy resin replicas were made. The scanning electron micrographs of each third section of the teeth were combined using Image Analyst software and measured with AutoCAD-2002. We obtained percentage values of the interfacial continuity. Results: Interfacial continuity was similar in the apical, medium and cervical thirds of the roots within the groups (Friedman test, $\mathrm{p}>0.05)$. Comparison of the different cements in a same root third showed that interfacial continuity was lower in $M X C(C=45.5 \% ; M=48.5 \% ; A=47.3 \%)$ than in $A C(C=85.9 \%$, $M=81.8 \%$ and $A=76.0 \%), A R C(C=83.8 \%, M=82.4 \%$ and $A=75.0 \%)$ and $U 100(C=84.1 \%$, $M=82.4 \%$ and $A=77.3 \%$ ) (Kruskal-Wallis test, $p<0.05$ ). Conclusions: Allcem, Rely X ARC and $\mathrm{U} 100$ provide the best cementation; cementation was similar among root portions; in practical terms, U100 is the best resin because it combines good cementation and easy application and none of the cements provides complete interfacial continuity.
\end{abstract}

Keywords: Post and core technique. Resin cements. Dental marginal adaptation. Dentinbonding agents.

\section{INTRODUCTION}

After the development of fiber-reinforced composite posts, adhesive resin cement systems are a good option for restoring endodontically treated teeth. However, the development of adhesive materials that form a continuous, strong and durable interface with tooth root is still a challenge. A complete filling of the root canal is expected to form a monoblock, a solid mass without gaps that seals the root perfectly and remains stable in the oral environment ${ }^{22}$. According to this concept, the monoblock is strong enough to support mastication and dissipates resistance capacity throughout the remaining tooth structure ${ }^{25}$. This is theoretical, however, and currently available adhesives do not provide a hermetic, leak proof seal ${ }^{22}$.

Conventional dual-cure resin cements are indicated for luting procedures because they have low solubility, high mechanical quality and adhesive properties ${ }^{19}$. The characteristics of the dual-cure cements are independent and complementary to 
those of light-activated chemical cements, which makes them ideal for deep cavities such as the root canal19,22. The use of dual-cure cements requires pretreatment of the tooth root with an adhesive system. Until a few years ago, most adhesive systems available were applied in a 3-step procedure, which were later combined into 2 steps and more recently, into a single self-etching application step. However, acid resinous monomers present in the surface layer of the 2-step and selfetching systems can weaken the adhesive binding to root dentin $6,9,15,24$. The permeability of simplified adhesives therefore results in water movement, even in root-treated dentin. This may adversely affect the coupling of auto-/dual-cured resin cements ${ }^{5,7}$.

Recently developed self-adhesive resin cements do not require pretreatment of the dentin. Because these cements do not use an adhesive system, they drastically reduce the number of application steps, shortening clinical treatment time and decreasing technique sensitivity since it minimizes procedural errors throughout the treatment phases $12,17,18,28$. Self-adhesive cements contain multifunctional phosphoric acid methacrylates that are reputed to react with the hydroxyapatite of hard tooth tissue. However, some studies suggest that selfadhesive cements have limited capacity to diffuse and decalcify the underlying dentin effectively ${ }^{15,17}$. Some reasons for this limitation are: 1) high viscosity, which may rapidly increase after acidbase reactions, and 2) a neutralization effect that may occur during setting, resulting in the release of water and of alkaline filler that raises $\mathrm{pH}$ level and buffering components of the smear layer ${ }^{17,29}$. These materials are relatively new and detailed information on their composition and adhesive properties is limited.

Debonding is the main failure in treatments using fiber-reinforced composite posts ${ }^{4}$. This is commonly caused by the inefficiency of the adhesive system or of the self-adhesive resin cements and occurs at distinct levels of the root canal. The apical portion of the root is particularly vulnerable to debonding because in this area it is difficult to eliminate the smear layer or remaining sealer/ gutta-percha ${ }^{18}$, control moisture ${ }^{7,29}$ and apply the adhesive $^{25}$. All these factors compromise bond strength and consequently, interfacial continuity 6 . In addition, dual-cure resin cements have limited ability to diffuse light across the entire length of resin cement, thereby compromising the degree of polymerization and conversion ${ }^{17,19}$.

Interfacial gaps are always found in bonded posts $^{3,13,20}$. Interfacial discontinuity is commonly attributed to resin shrinkage $e^{3,20,24}$ because the strength of polymerization contraction often exceeds dentin adhesiveness, forming interfacial gaps at sites with weakened bonds along the dentin surface 20,24 . Root canal geometry is also unfavorable for resin bonding, as evidenced by the ratio of bonded to unbounded surface ${ }^{3,15,24}$. With respect to clinical treatment with glass fiber posts, however, some authors ${ }^{13,20}$ assert that dentin bonding is more related to the dislocation resistance promoted by sliding friction and surface roughness than to shrinkage stress or canal geometry. Discontinuity in binding interface is a serious failure in endodontic procedures because pull off or debonding may shorten treatment duration ${ }^{24}$ and cause bacterial proliferation and infiltration ${ }^{16,26}$.

The interface formed by the main resin cements currently used should be further investigated to improve the efficiency and durability of endodontic treatments. We therefore evaluated the continuity of dentin-cement interface formed by dual-cure and self-adhesive cements. We hypothesized that, despite the complex application, dual-cure cements form a more continuous interface compared to their self-adhesive counterpart. Because geometry and environmental conditions are quite irregular along the root portions, we tested a second hypothesis that the interfacial continuity formed is different in the cervical, medium and apical portions of the root.

\section{MATERIAL AND METHODS}

For the present study we selected 40 singlerooted human teeth that had been extracted for orthodontic or periodontal reasons after approval by the Research Ethics Committee (approval \# $753 / 2006)$. They were cleaned and stored in a $0.9 \%$ solution of thymol and their crowns were cut to a standard root length of $14 \mathrm{~mm}$.

The roots were instrumented up to a \#45 $K$ file (Maillefer, Dentsply Maillefer Ind. e Com Ltda. Petrópolis, Rio de Janeiro, Brazil) at the working length, and they were irrigated with $2 \%$ chlorhexidine digluconate solution (Clorhexidina, FGM - Dental Products Ltd., Joinville, SC, Brazil). They were filled with gutta-percha (Maillefer, Dentsply Ind. e Com Ltda. Petrópolis, Rio de Janeiro, Brazil) and Sealer 26 root canal sealer (Sealer 26, Dentsply Ind. e Com Ltda., Petrópolis, Rio de Janeiro, Brazil) using the hybrid thermoplastic technique described by Tagger $^{23}$ (1984). The coronal access of the roots were sealed with temporary restorative cement, Coltosol (Coltosol, Vigodent S/A Ind. e Com, Rio de Janeiro, Brazil) and stored in a bottle with moistened foam in a microprocessor controlled incubator used for cell culture and bacteriology (Model Q326M2, Callmex - Products and Services Laboratory, Florianópolis, SC, Brazil) at $37^{\circ} \mathrm{C}$ for 7 days. 


\section{Preparation of the root canals}

The samples were prepared at $10 \mathrm{~mm}$, using a \# 3 Largo drill (Maillefer, Dentsply Maillefer Ind. e Com Ltda. Petrópolis, Rio de Janeiro, Brazil), compatible to the glass-fiber post REFORPOST \#01 (20 mm length, $0.7 \mathrm{~mm}, \varnothing \mathbf{1} 1.1 \mathrm{~mm}$ ) (Reforpost, Angelus ( Ind. e Com Ltda. Londrina, PR, Brazil). The glassfiber posts were tested into the root canal prepared and then cut in $14 \mathrm{~mm}$ length. The teeth and their posts were separated randomly into 4 groups of 10 samples according to the cement used.

\section{Fiber-reinforced composite post preparation}

The posts were cleaned with $70 \%$ alcohol for 1 minute, followed drying. Afterwards, the silane coupling agent (Silano Angelus, Angelus $($ Ind. $\mathrm{e}$ Com. Ltda. Londrina, PR, Brazil) was applied on the post surface during $1 \mathrm{~min}$. The hydrophobic adhesive Adper ScotchBond Plus Multi-Purpose (Adper $^{\mathrm{TM}}$ ScotchBond ${ }^{\mathrm{TM}}$ Plus Multi-Purpose, 3M ESPE, Sumaré, SP, Brazil) was applied to the post, light-curing for $20 \mathrm{~s}$, using Radii curing light (Radii LED curing light, SDI, Bayswater, Victoria, Australia) at an intensity of $1200 \mathrm{~mW} / \mathrm{cm}^{2}$.

\section{Post luting procedure}

The compositions of the cements and resin adhesive system are shown in Figure 1.

Group AC: AllCem conventional dual-cure resin cement (AllCem, FGM - Dental Products Ltd., Joinville, SC, Brazil), and Group ARC: RelyXTM ARC conventional dual-cure resin cement (RelyXTM ARC, 3M ESPE, Sumaré, SP, Brazil). Both groups had the same treatment of the root canal. The root dentin was conditioned for $15 \mathrm{~s}$ with $37 \%$ phosphoric acid gel (Cond AC 37, FGM-Dental Products Ltd., Joinville, SC, Brazil); it has been washed with distilled water and dried with an endodontic aspirator and absorbent paper points. The Adper ScotchBond Plus Multi-Purpose adhesive system (AdperTM ScotchBondTM Plus Multi-Purpose, 3M ESPE, Sumaré, SP, Brazil) was applied in the following sequence: first, the activator was applied with the microbrush, and after 30 s the excess was removed with absorbent paper; the same process was then repeated with the Primer and catalyst. The cement was manipulated and inserted into the canal with Centrix ${ }^{\circledR}$ syringe and needle headed (Centrix, DFL Ind. e Com SA, Rio de Janeiro, RJ, Brazil).

\begin{tabular}{|c|c|c|}
\hline $\begin{array}{l}\text { Resin cement } \\
\text { (batch number) }\end{array}$ & Composition of the resin cement & $\begin{array}{l}\text { Composition of the adhesive } \\
\text { system (batch number) }\end{array}$ \\
\hline $\begin{array}{l}\text { Allcem dual cure (71007) } \\
\text { FGM, Joinville, PR, Brazil }\end{array}$ & $\begin{array}{l}\text { Base paste: TEGDMA, BisEMA, BisGMA, } \\
\text { camphoroquinone barium-aluminum-silicate } \\
\text { microglass, silica nanoparticles; } \\
\text { Catalyst paste: methacrylic monomers, dibenzoyl } \\
\text { peroxide and stabilizers, barium-aluminum-silicate } \\
\text { microparticles of } 66-67 \text { wt } \% \text { over the mixture. }\end{array}$ & $\begin{array}{l}\text { Component 1,5 (activator) }(7 \mathrm{KY}) \\
\text { ethanol, sulfinic acid salt, sodium salt. } \\
\text { Component } 2 \text { (Primer) (7BP) HEMA, } \\
\text { polyalkenoic acid polymer, water. }\end{array}$ \\
\hline $\begin{array}{c}\text { RelyX ARC dual } \\
\text { cure }(\mathrm{GCHJ}) 3 \mathrm{M} \\
\text { ESPE,Sumaré, SP, Brazil }\end{array}$ & $\begin{array}{c}\text { Paste A: BisGMA, TEGDMA, } 68 \% \text { by weight } \\
\text { zirconia/silica filler, pigments, amine and } \\
\text { photoinitiator system. } \\
\text { Paste B: } 67 \% \text { by weight zirconia/silica filler, } \\
\text { benzoyl peroxide }\end{array}$ & $\begin{array}{c}\text { Component 3,5 (catalyst) (7BB) } \\
\text { BisGMA, HEMA, BPO. }\end{array}$ \\
\hline $\begin{array}{c}\text { RelyX U100 self- } \\
\text { cure (321638) 3M } \\
\text { ESPE,Sumaré, SP, Brazil }\end{array}$ & $\begin{array}{l}\text { Base: glass fiber, multifunctional methacrylate } \\
\text { phosphoric acid monomers, dimethacrylates, } \\
\text { silanated silica, sodium persulfate. } \\
\text { Catalyst: glass fiber, dimethacrylates, silanated } \\
\text { silica, p-toluene sodium sulfate, calcium hydroxide }\end{array}$ & - \\
\hline $\begin{array}{c}\text { Maxcem Elite self } \\
\text { cure (3018537) Kerr } \\
\text { Corporation, Orange, } \\
\text { CA,USA }\end{array}$ & $\begin{array}{l}\text { Resin matrix: GPDM, co-monomers (mono-, } \\
\text { di-, and tri-functional methacrylate monomers), } \\
\text { proprietary self-curing redox activator, } \\
\text { photoinitiator } \mathrm{CQ} \text {, stabilizer } \\
\text { Filler load } 67 \% \text { wt: fluoroaluminiosilicate glass, } \\
\text { fumed silica, barium glass, ytterbium fluoride }\end{array}$ & - \\
\hline
\end{tabular}

GPDM - glycerol dimethacrylate dihydrogen phosphate

$\mathrm{CQ}$ - camphorquinone

TEGDMA - triethylenglycol dimethacrylate

BisEMA - ethoxylated bisphenol A glycol dimethacrylate

Figure 1- Chemical compositions of the resinous cements and adhesive systems 
The posts were then inserted, the excess cement removed and the remaining cement cured for 40 $\mathrm{s}$ on the occluded surface with a Radii curing light (Radii LED curing light, SDI, Bayswater, Victoria, Australia) at an intensity of $1200 \mathrm{~mW} / \mathrm{cm}^{2}$.

Group U100: RelyX ${ }^{\mathrm{TM}}$ U100 universal selfadhesive resin luting cement (RelyX $\mathrm{X}^{\mathrm{TM}} \mathrm{U100}$, 3M ESPE, Sumaré, SP, Brazil), and Group MXC: Maxcem Elite dual self-adhesive resin luting cement (Maxcem Elite, Kerr Corporation, Orange, CA, USA). On the cementing procedure, the treatment of the root canal with etching agent was omitted. Instead, the root canal was washed on distilled water; the cement was inserted with Centrix $\AA$ syringe and needle headed (Centrix, DFL Ind. Com. S.A., Rio de Janeiro, RJ, Brazil). The posts were inserted, the excess cement was removed and the remaining cement cured for $40 \mathrm{~s}$ on the occluded surface, with a Radii curing light.

The posts and canals were sealed with Opallis composite resin (Opallis, FGM, Joinville, SC, Brazil), and the samples were stored for 72 hours at $100 \%$ humidity and $37^{\circ} \mathrm{C}$ in a microprocessor-controlled incubator used for cell culture and bacteriology (Model Q326M2, Callmex - Produtos e Serviços Para Laboratório, Florianópolis, SC, Brazil).

\section{Adequacy of the samples for mechanical test}

After storaging, the roots were sectioned with an IsoMet Low Speed Saw (IsoMet ${ }^{\circledR}$, BUEHLER LTD., Lake Bluff, IL, USA). The samples were cleaned with $10 \%$ liquid phosphoric acid for $10 \mathrm{~s}$, washed and submitted to ultrasound (Ultra Cleaner 1400A, Unique, Indaiatuba, São Paulo, Brazil) for $10 \mathrm{~min}$.

To obtain realistic results, the present study used positive epoxy resin replicas of the samples after root sectioning to preserve the interface integrity between the different resin cements and the canal wall dentin.

They were then dried with an air jet, negative molds were produced using addition silicone (Adsil, Vigodent, Rio de Janeiro, RJ, Brazil), and positive replicas were made with epoxy resin (Epóxi, Redelease, São Paulo, SP, Brazil). Two marks were made in the positive replicas in the region of the root dentin 3 and $6 \mathrm{~mm}$ from the cervical end with the aid of a scalpel for guidance when taking measurements. The replicas were cleaned in an ultrasonic bath for $10 \mathrm{~min}$. and metalized, and electron micrographs of each third of the root were taken using a scanning electron microscope (SEM), operating at $15 \mathrm{kV}$ (JEOL JSM-5410, Jeol Ltd, Tokyo, Japan) (35x and 200x magnification).

The Image Analyst program was used to combine the electron micrographs making up each root to measure the length of the interfacial continuity (Figure 2). The combined electron micrographs (35x

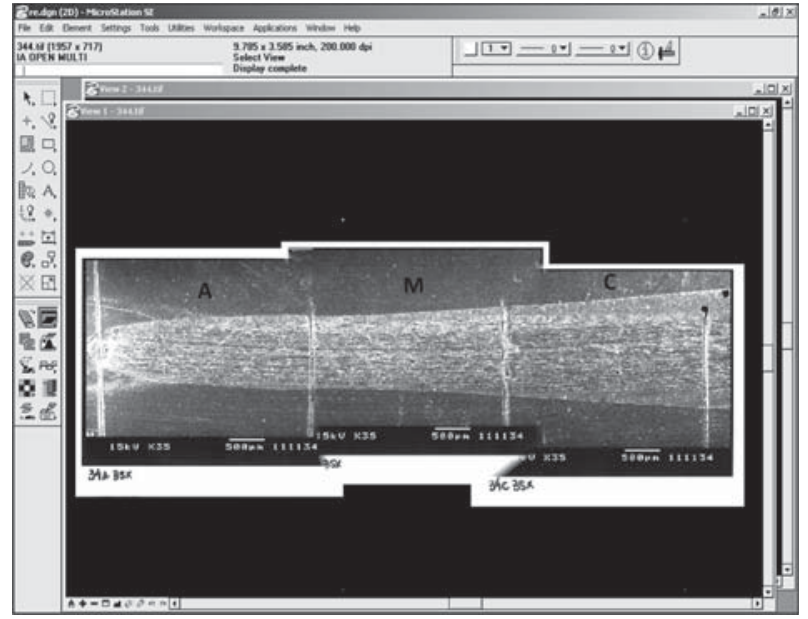

Figure 2- Scanning electron micrographs of the cervical $(\mathrm{C})$, medium (M) and apical (A) thirds combined using Image Analyst software. Original magnification, 40x

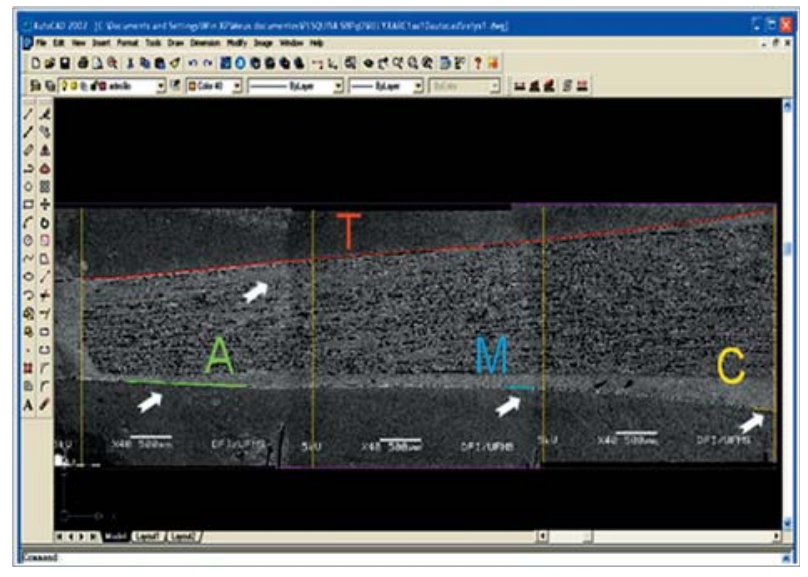

Figure 3- Measurements taken with the AutoCAD 2002 software: total length $(T)$ of the thirds and lengths of the attached sections (C, M, A). Original magnification, 40x

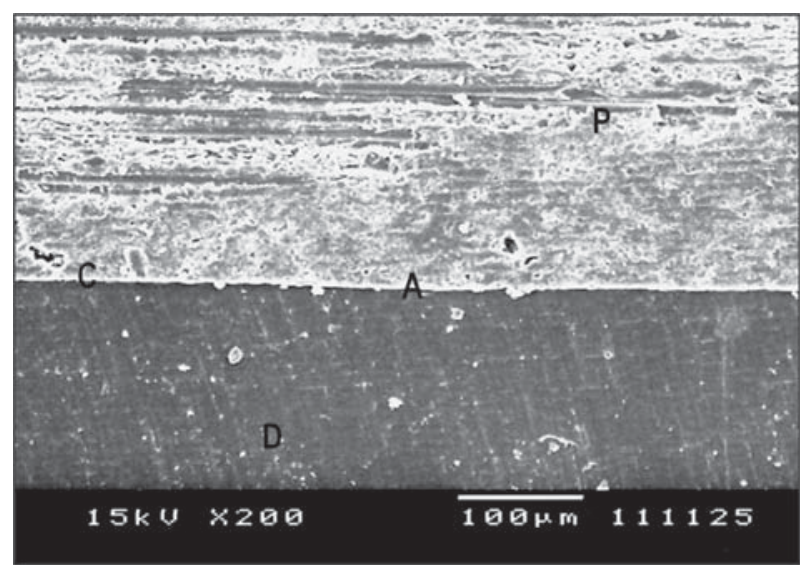

Figure 4- Representative electron micrograph of the third; interfacial adaptation $(C=$ cement; $D=$ dentin; $P=$ post; $A=$ interface continuity). Original magnification, 200x 


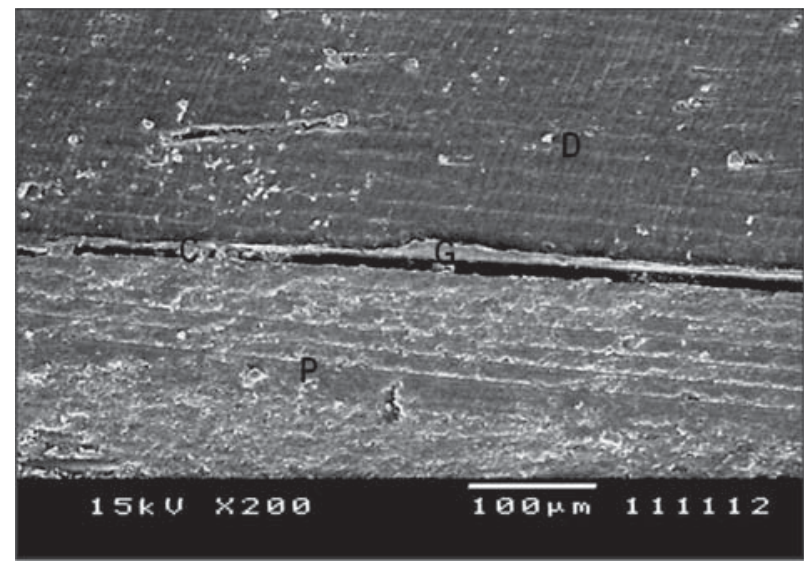

Figure 5- Electron micrograph of a representative third; interfacial misfit $(C=$ cement; $D=$ dentin; $P=$ post; $G=g a p)$. Original magnification, 200x

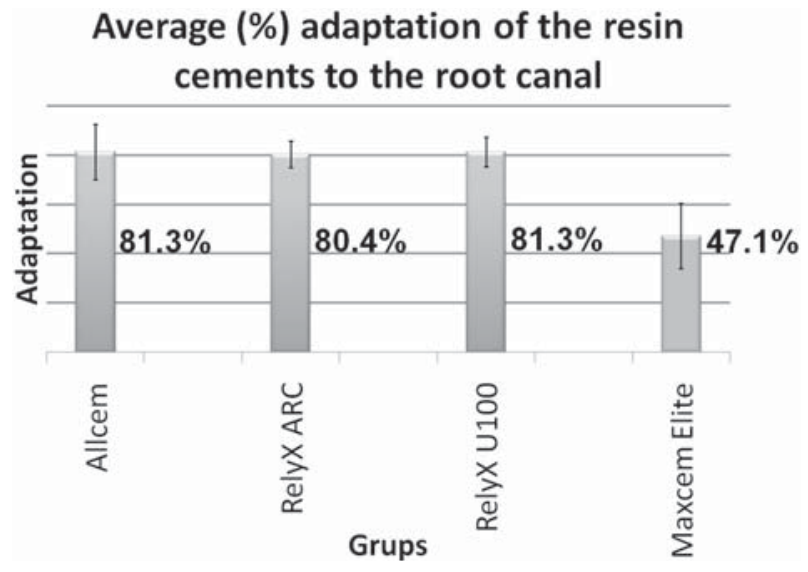

Figure 6- Median of the total interfacial adaptation along the root canal for the resin cements

Table 1- Mean percentage of the interfacial continuity resin cements (\%) and standard deviation varying the cervical, medium and apical thirds

\begin{tabular}{lccccc}
\hline & AC & ARC & U100 & MXC & P \\
\hline Cervical & $85.9 \pm 11.4^{\mathrm{A}, \mathrm{a}}$ & $83.8 \pm 9.4^{\mathrm{A}, \mathrm{a}}$ & $84.1 \pm 9.1^{\mathrm{A}, \mathrm{a}}$ & $45.5 \pm 19.8^{\mathrm{A}, \mathrm{b}}$ & 0.0001 \\
Medium & $81.8 \pm 12.7^{\mathrm{A}, \mathrm{a}}$ & $82.4 \pm 12.4^{\mathrm{A}, \mathrm{a}}$ & $82.4 \pm 7.5^{\mathrm{A}, \mathrm{a}}$ & $48.5 \pm 11.7^{\mathrm{A}, \mathrm{b}}$ & 0.0001 \\
Apical & $76.0 \pm 15.8^{\mathrm{A}, \mathrm{a}}$ & $75.0 \pm 10.0^{\mathrm{A}, \mathrm{a}}$ & $77.3 \pm 9.2^{\mathrm{A}, \mathrm{a}}$ & $47.3 \pm 18.1^{\mathrm{A}, \mathrm{b}}$ & 0.0013 \\
Total & $81.3^{\mathrm{a}} \%$ & $80.4 \%$ & $81.3^{2} \%$ & $47.1 \%$ & 0.0000 \\
$\mathbf{P}$ & 0.1496 & 0.1496 & 0.6703 & 0.7985 & \\
\hline
\end{tabular}

Comparison between columns: same capital letters indicate no statistically significant difference.

Comparison between lines: same lower case letters indicate no statistically significant difference.

magnification) were then analyzed with AutoCAD 2002 software, and the following measurements were taken the length of each third of the root and the sum of the interfacial continuity. The integrity of the interface in each third was then expressed as the percentage of continuous (gap-free) interface. The percentage of the continuous interface along the entire cement/radicular dentin interface was also calculated (Figure 3 ). Figure 4 shows what was considered interfacial continuity and Figure 5 shows a misfit.

\section{RESULTS}

Friedman and Kruskal-Wallis tests with an $\alpha \leq 5 \%$ were used to determine whether there were any statistically significant differences in the results for the resin cements tested.

Friedman test revealed no statistically significant differences among the thirds of the roots for each group: Group AC $(p=0.1496)$, Group ARC $(p=0.1496)$, Group U100 $(p=0.6703)$ and Group MXC $(p=0.7985)$. These results are shown in Table 1.

The Kruskal-Wallis and Dunn tests revealed a statistically significant difference between cements for each of the three thirds of the roots. Groups AC, $A R C$ and U100 showed better performance than Group MXC for cervical thirds $(p=0.0001)$, medium thirds $(p=0.0001)$ and apical thirds $(p=0.0013)$ (Table 1).

However, interfacial discontinuity could be observed in all root regions. Taking into account the overall interfacial continuity of the cements, it was observed that $U 100>A C>A R C>M X C$ (Figure 6).

\section{DISCUSSION}

Corroborating the first hypothesis of the present study, both the dual-cure resin cements tested in vitro produced a more continuous interface than the self-adhesive Maxcem, which formed a discontinuous interface with many gaps. However, contradicting this same hypothesis, the interfacial continuity produced by U100 self-adhesive cement was as satisfactory as that formed by the dual-cure cements. In relation to root portion, we rejected the hypothesis concerning different cement adhesion in the cervical, medium and apical root regions.

For the experimental assays, we used a reliable technique involving epoxy resin replicas, which avoided a possible influence of shrinkage under 
vacuum in scanning electron microscopy. This method is widely used to investigate adhesion in root canals $2,7,9,17,20,21$.

A number of variables can compromise cement adhesion, such as root dentin morphology ${ }^{9}$, humidity $^{7}$, adhesive system capabilities ${ }^{17,29}$, compatibility of adhesive system and dual-cured luting cement ${ }^{29}$, deep light cure capabilities ${ }^{11}$, light transmissibility of fiber posts ${ }^{11,29}$, polymerization shrinkage and relief of shrinkage stress. The use of an adequate resin cement system is particularly important for cement adhesion because it directly affects the quality of the tooth-luting interface. Dual self-adhesive resin cements generally have better adhesion than self-adhesive resin cements, suggesting that composite materials significantly influence the formation of the tooth-luting interface ${ }^{1,2,10,29}$. Corroborating this hypothesis $t$, both dual self-adhesive resin systems tested here (Allcem and RelyX ARC) exhibited good adaptation and low gap formation $(A C=81.3 \%$ and $A R C=80.4 \%$ interfacial continuity; Table 1 ).

Conventional dual-cure resin cements can be used in adhesive systems that require pretreatment of the root with phosphoric acid as etching solution followed by the application of a 2- or 3-step adhesive system. We used a 3-step system, and the quality of this product undoubtedly contributed to the good results obtained for groups $A C$ and

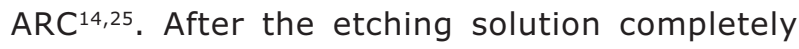
dissolves the smear layer and creates a partially demineralized zone of dentin, the 3-step adhesive system is applied using an activator followed by a primer and a catalyst (Adper Scotchbond Multipurpose Plus). The 3-step etch \& rinse adhesive system increases the interfacial adaptation of dualcure luting cement because it increases adhesive penetration into dentinal tubules, thereby improving the pattern of dentin hybridization $7,14,16,21,25$. The catalyst layer of the 3-step system $(\mathrm{pH}=5.7)^{27}$ is not composed of solvents that could allow a few droplets to transude the polymerized adhesive and compromise cement adhesion ${ }^{7}$. In addition, the 3-step adhesive system lacks acid monomers, which ensures total compatibility with the dualcure luting cement. Other adhesive systems, such as 2-step and one-step-self-etch, have uncured acidic resin monomers in the oxygen inhibition layer that are incompatible with the tertiary amines (initiator component) involved in the polymerization mechanism of dual-cure resin cements ${ }^{2,6,22}$.

Decreased $\mathrm{pH}$ is another disadvantage of adhesive systems containing acid monomers because it weakens bond strength. Conversely, the 3-step system provides effective binding between the adhesive agents and the dental structure $2,5,17$. The catalyst used, Scotchbond Multi-Purpose Plus, contains a common initiator for self-curing resins, benzoylperoxide (BPO), which reacts with the tertiary amines of the self-cure and dual-cure resin cements ${ }^{27}$ and helps dual polymerization of the dual-luting cement along the root. Other advantages of the 3-step adhesive system is that no light curing is required before post cementation ${ }^{27}$, overcoming an obstacle in curing deep regions.

In addition to pretreatment, the composition of dual-cure resin cements unquestionably contributed to cementing quality. These resin cements contain cross-linking monomers such as Bis-GMA, which produce polymers of high mechanical quality because of their high molecular weight, low polymerization contraction and rapid hardening 27 . Dual-cure resin cement also contains the monomer diluent triethylene glycol dimethacrilate (TEGDMA), which has high flexibility and low polymerization contraction. TEGDMA also provides a high degree of conversion and has hydrophobic properties that prevent substantial water uptake after curing. Compared to Bis-GMA, TEGDMA allows better clinical handling owing to its low viscosity ${ }^{27}$. A redox reaction of benzoyl peroxide of dual-cure resin cements with aromatic tertiary amines underlies the setting mechanism, a process that is compatible with the 3-step adhesive system, as mentioned before.

Similarly to the conventional dual-cure cements tested here, the U100 self-adhesive cement exhibited good performance (Table 1). Earlier studies reported satisfactory results using RelyX Unicem cement, which is chemically identical to the RelyX U100 we tested, differing only in the application procedure. RelyX Unicem produces good marginal continuity, but due to its high viscosity, does not form an obvious dentin hybrid layer and thus achieves limited infiltration ${ }^{12,17}$. Therefore, both RelyX U100 and RelyX Unicem are highly adapted to the substrate and can optimize physical interactions such as van der Waals forces, hydrogen bridges and charge transfer, which enhance micromechanical retention and chemical bonding ${ }^{12}$.

The multifunctional, phosphoric acid modified methacrylate monomers of $\mathrm{U} 100 \quad(\mathrm{pH}<2)$ demineralize root dentin as well as infiltrate the substrate and react with the hydroxyapatite of hard tissues $1,17,28$. Thus, the micromechanical retention associated to the chemical adhesion to hydroxyapatite provides self-adhesiveness to the U100 cement (3M ESPE technical information). This chemical interaction produces water, which accelerates neutralization of phosphoric-acid methacrylate, basic fillers and hydroxyapatite 1,28,29. The system likely gained water resistance, and although water and buffering of the smear layer may have reduced desmineralization capacity, the effectiveness of the U100 cement was not compromised, as reported in earlier study ${ }^{18}$. Overall, 
we consider that RelyX U100 cement is the best of the tested cements because, in addition to the good results it obtained, its application is significantly easier than that of conventional dual care cements.

In contrast to U100, Maxcem self-adhesive cement performed poorly, corroborating earlier studies $^{12,18,28}$. Maxcem contains several hydrophilic adhesive monomers of low molecular weight, such as the glycerol phosphate dimethacrylate (GPDM), which provide the necessary wettability for adhesion to dentin substrate. The cement is purportedly anhydrous prior to mixing, but the technical specifications of this product do not inform the way this monomer is initially hydrolyzed, the initial $\mathrm{pH}$ or the proprietary redox activator system ${ }^{12}$. GPDM forms polymers with high flexibility albeit of low quality $^{27}$. This may account for the discontinuous tooth-cement interface, with many premature failures, that we found in the MXC group. Maxcem has limited potential for removal or modification of the smear layer and low resin infiltration into the underline dentin ${ }^{12,18,28}$. Therefore, it does not form a dentin hybrid layer that promotes the micromechanical interlocking with dentin collagen fibrils ${ }^{12,17}$. The thick smear layer formed neutralizes the initial low $\mathrm{pH}$ of Maxcem thereby impairing its performance ${ }^{10,12}$. Therefore, despite the excellence of Maxcem monomers as bonding agents of good compatibility with the humid dentin substrate, they do not provide an effective cementation in deep areas of high humidity. We however have not found cementation differences in the wettest and driest portions of the root, and the bad results of Maxcem may derive from poor-quality of the polymer formed.

For practical reasons we have not investigated chemical set cements. But some concerns should be made on these materials because they are widely used in endodontic treatments despite the application failures reported in other studies. These cement sets have a long setting time, with a prolonged gelation that possibly reliefs shrinkage stress via resin flow fl, $^{2,15}$. This long setting time, however, allows moisture diffusion from the dentin through the hydrophilic primer, creating water blisters or droplets along the interface with the slow polymerizing resin cements ${ }^{2}$. Moisture contamination reduces bond strength and facilitates leaching of water-soluble components from the resin. This process is as serious as the incompatibility of adhesive systems and may further contribute to break down the bond, as show in both in vitro ${ }^{2}$ and in vivo studies ${ }^{7}$ of endodontically treated teeth.

Some studies on the adhesive resistance of cements show that binding is stronger in the cervical portion and weaker in the apical portion of the $\operatorname{root}^{3,18}$. Some authors suggest that samples of low bond strength have a high number of gaps ${ }^{1,29}$, but the relationship between bond strength and bond integrity has not yet been proved ${ }^{1,20}$. In accordance with other authors ${ }^{1,10,15,21,25,29}$, we in fact found that the experimental groups had a same pattern of continuity interface throughout the apical, medium and cervical portions of the root. We expected to find a higher continuity in the cervical portion of the root because the curing light absorbed along the canal decreases significantly light incidence in the medium and apical portions. This is minimized when light-transmitting posts are used ${ }^{11}$ because they improve polymerization in deep areas of canal roots ${ }^{21}$. In our study, however, we used opaque posts ${ }^{11}$ and did not found that drops in light incidence have affected interfacial continuity ${ }^{21}$. The cervical third of the root had higher cement thickness, but variations of this parameter did not affect interfacial continuity as well. The major implication of a high cement thickness is the shrinkage risk with consequent debonding and gap formation in the resin cement/dentin interface ${ }^{13,20,25}$. In the present study, differences in cement thicknesses were rather related to the uneven root anatomy than to interface quality.

Continuity of dentin/cement interface is necessary to promote sliding friction, which according to many authors is the main factor for adhesive resistance in the fiber post/resin cement system ${ }^{13,14,20}$ and for micromechanical interlocking ${ }^{25}$. As already observed by practitioners in routine treatments, our results show that the cements currently used provide good cementation but do not form a complete bonding and a continuous interface along the length of the root channel ${ }^{3,24,25}$. Complete fiber luting is important because it prevents post displacement by frictional retention ${ }^{13,14}$ and bacterial leakage ${ }^{16}$, thereby enhancing the longevity of coronal restorations in endodontically treated teeth $^{8,26}$. According to Schwartz ${ }^{22}$ (2006) and Tay, Loushine, Lambrechts, et al. ${ }^{24}$ (2005) adequate adhesive resin systems should not suffer shrinkage stress. Therefore, more attention should be devoted to the recently developed low-shrinking resin composites that have been used only for tooth restorations. We therefore suggest the adaptation of these resins to endodontic treatments such as post luting. This is a promising resin to prevent gap formation in the dentin-adhesive interface.

\section{CONCLUSIONS}

Based on the results of this in vitro study, we conclude that:

1 - The cements Allcem, RelyX ARC and RelyX U100 provide good cementation with $80 \%$ continuity. Maxcem Elite does not produce a satisfactory cementation (only $47 \%$ interfacial 
continuity);

2 - Cementation quality provided by the different cement types is similar among the cervical, medium and apical portions of the tooth roots;

3 - In practical terms, RelyX U100 provides the best cementation because combines good cementation and easy application;

4- Because the cements tested do not provide a complete interfacial continuity, we suggest the development of novel materials using lowshrinking resin composites that are already used for restoration purposes.

\section{ACKNOWLEDGMENTS}

The authors would also like to thank by fiber post, luting cements generously donated by Ângelus, FGM, KERR and 3M ESPE. Authors acknowledge institutional UFMS support of staff and facilities for this study.

\section{REFERENCES}

1- Bitter K, Paris S, Pfuertner C, Neumann K, Kielbassa AM. Morphological and bond strength evaluation of different resin cements to root dentin. Eur J Oral Sci. 2009;117(3):326-33. 2- Bonfante EA, Pegoraro LF, Góes MF, Carvalho RM. SEM observation of the bond integrity of fiber reinforced composite post cemented into root canals. Dent Mater. 2008;24(4):483-91. 3- Bouillaguet S, Troesch S, Wataha JC, Krejci I, Meyer JM, Pashley $\mathrm{DH}$. Microtensile bond strength between adhesive cements and root canal dentin. Dent Mater. 2003;19(3):199-205.

4- Cagidiaco MC, Goracci C, Garcia-Godoy F, Ferrari M. Clinical studies of fiber posts: a literature review. Int J Prosthodont. $2008 ; 21(4): 328-36$.

5- Carvalho RM, Garcia FCP, Silva SM, Castro FL. Critical appraisal: adhesive-composite incompatibility, part I. J Esthet Restor Dent. 2005;17(2):129-34.

6- Carvalho RM, Garcia FCP, Silva SM, Castro FI. Critical appraisal: adhesive-composite incompatibility, part II. J Esthet Restor Dent. 2005; 17(3):191-5.

7- Chersoni S, Acquaviva GL, Prati C, Ferrari M, Grandini S, Pashley $\mathrm{DH}$, et al. In vivo fluid movement through dentin adhesives in endodontically treated teeth. J Dent Res. 2005;84(3):223-7.

8- Ferrari M, Cagidiaco MC, Grandini S, De Sanctis M, Goracci C. Post placement affects survival of endodontically treated premolars. J Dent Res. 2007;86(8):729-34.

9- Ferrari M, Mannocci F, Vichi A, Cagidiaco MC, Mjör IA. Bonding to root canal: structural characteristics of the substrate. Am J Dent. 2000;13(5):255-60.

10- Foxton RM, Nakajima M, Tagami J, Miura H. Adhesion to root canal dentine using one and two-step adhesives with dual-cure composite core materials. J Oral Rehabil. 2005;32(2):97-104. 11- Goracci C, Corciolani G, Vichi A, Ferrari M. Light-transmitting ability of marketed fiber posts. J Dent Res. 2008;87(12):1122-6. 12- Goracci C, Cury AH, Cantoro A, Papacchini F, Tay FR, Ferrari M. Microtensile bond strength and interfacial properties of self-etching and self-adhesive resin cements used to lute composite onlays under different seating forces. J Adhes Dent. 2006;8(5):327-35.
13- Goracci C, Fabianelli A, Sadek FT, Papacchini F, Tay FR, Ferrari $M$. The contribution of friction to the dislocation resistance of bonded fiber posts. J Endod. 2005;31(8):608-12.

14- Goracci C, Sadek FT, Fabianelli A, Tay FR, Ferrari M. Evaluation of the adhesion of fiber post to intraradicular dentin. Oper Dent. 2005;30(5):627-35.

15- Goracci C, Tavares AU, Fabianelli A, Monticelli F, Raffaelli O, Cardoso PC, Tay F, et al. The adhesion between fiber posts and root canal walls: comparison between microtensile and push-out bond strength measurements. Eur J Oral Sci. 2004;112(4):353-61. 16- Mannocci F, Bertelli E, Watson TF, Ford TP. Resin-dentin interface of endodontically-treated restored teeth. Amer J Dent. 2003;16(1):28-32.

17- Monticelli F, Osorio R, Mazzitelli C, Ferrari M, Toledano M. Limited decalcification/diffusion of self-adhesive cements into dentin. J Dent Res. 2008;87(10):974-9.

18- Mumcu E, Edemir U, Topcu FT. Comparison of micro push-out bond strengths of two fiber posts luted using simplified adhesive approaches. Dent Mater J. 2010;29(3):286-96.

19- Pedreira APRV, Pegoraro LF, Góes MF, Pegoraro TA, Carvalho RM. Microhardness of resin cements in the intraradicular environment: effects of water storage and softening treatment. Dent Mater. 2009;25(7):868-76.

20- Pirani C, Chersoni S, Foschi F, Piana G, Loushine RJ, Tay FR, et al. Does hybridization of intraradicular dentin really improve fiber post retention in endodontically treated teeth? J Endod. 2005;31(12):891-4.

21- Radovic I, Corciolani G, Magni E, Krstanovic G, Pavlovic V, Vulicevic Z, et al. Light transmission through fiber post: the effect on adhesion, elastic modulus and hardness of dual-cure resin cement. Dent Mater. 2009;25(7):837-44.

22- Schwartz RS. Adhesive dentistry and endodontics. Part 2: bonding in the root canal system - the promise and the problems: a review. J Endod. 2006;32(12):1125-34.

23- Tagger M, Tamse A, Katz A, Korzen BH. Evaluation of the apical seal produced by a hybrid root canal filling method, combining lateral condensation and thermatic compaction. J Endod. 1984;10(7):299-303.

24- Tay FR, Loushine RJ, Lambrechts P, Weller RN, Pashley DH. Geometric factors affecting dentin bonding in root canals: a theoretical modeling approach. J Endod. 2005;31(8):584-9.

25- Teixeira CS, Felippe MCS, Silva-Sousa YTCM, Sousa-Neto MD. Interfacial evaluation of experimentally weakened roots restored with adhesive materials and fibre posts: an SEM analysis. J Dent. 2008;36(9):672-82.

26- Tronstad L, Asbjørnsen K, Døving L, Pedersen I, Eriksen HM. Influence of coronal restorations on the periapical health of endodontically treated teeth. Endod Dent Traumatol. 2000;16:218-21.

27- Van Landuyt KL, Snauwaert J, De Munck J, Peumans M, Yoshida $Y$, Poitevin A, et al. Systematic review on the chemical composition of contemporary dental adhesives. Biomaterials. 2007;28(26):3757-85.

28- Viotti RG, Kasaz A, Pena CE, Alexandre RS, Arrais CA, Reis AF. Microtensile bond strength of new self-adhesive luting agents and conventional multistep systems. J Prosthet Dent. 2009;102(5):306-12.

29- Zicari F, Couthino E, De Munck J, Poitevin A, Scotti R, Naert I, et al. Bonding effectiveness and sealing ability of fiber-post bonding. Dent Mater. 2008;24(7):967-77. 